Gut, 1987, 28, S1, 143-151

\title{
Intestinal cells produce basement membrane proteins in vitro
}

\author{
URSULA HAHN, D SCHUPPAN, E GHAHN, H-J MERKER, AND E-O RIECKEN \\ From the Div. of Gastroenterology, Dept of Medicine, Steglitz Medical School and Div. of Anatomy, Free \\ University of Berlin, West Berlin, FRG
}

SUMMARY The epithelial-mesenchymal interface of the intestinal mucosa obviously plays an important role in supporting the mucosal architecture. Its significance for the process of migration and differentiation of the epithelial cells remains to be resolved. It consists of a basement membrane, the anchoring zone and the subepithelial connective tissue, the origin of which is unknown. We therefore established an in vitro model to study the development of the endodermal-mesenchymal interface of the fetal human and murine intestinal mucosa. The distribution of the interstitial collagens type I, III, VI and procollagen type III as well as the basement membrane components collagen type IV and laminin was investigated immunohistochemically in these fetal explant cultures. The cultures were also adapted to serum free culture conditions. It was evident that while laminin and collagen type IV could be detected in the primary intestinal epithelium, the formation of an authentic basement membrane required the presence of both the epithelial and the mesenchymal cells. Interstitial collagens and procollagen type III were produced exclusively by the mesenchymal cells. Basement membrane formation in vitro coincided with cytodifferentiation of the endodermal cells as betrayed by electron microscopy and the activity of brush border enzymes. In conclusion, the maturation of the endoderm and the formation of the subepithelial basement membrane require the intimate proximity of viable mesenchyme in vitro.

The functional capacity of the small intestinal epithelium depends on the number and integrity of mature villus cells generated by the proliferative compartment of the crypts. While humoral factors and the adaptive response of the intestinal mucosa have been studied in detail to elucidate how the proliferation of the epithelium is regulated, little attention has been directed to the interaction of the epithelial cells with their extracellular matrix. Migration and terminal differentiation of the intestinal epithelial cells along the crypt-villus axis, however, imply that unique regulatory mechanisms should exist concerning the interaction of the epithelial cells, their basement membrane and the subepithelial connective tissue. Defective regulation of the migratory rate of the epithelial cells will alter cell turnover and hence the functional capacity of the mucosa.

Today we can apply the knowledge of the general biochemical composition and function of the extracellular matrix and the basement membranes that has expanded impressively over recent years. ${ }^{1-4}$ The

Address for correspondence: Dr Ursula Hahn, Jefferson Medical College, Room 403, 1025 Walnut St., Philadelphia, PA, 19107, USA. availability of specific antibodies to macromolecules of the extracellular matrix has intensified research in this area. ${ }^{56}$ Thus, the investigation of cell-matrix interactions in the gut at a molecular level has become feasible.

We have recently conducted a comprehensive survey on the distribution of collagen type I, III, IV, V, VI, procollagen type I and III, fibronectin, laminin and undulin in the human intestinal mucosa. ${ }^{7}$ Our studies have revealed a very homogenous appearance of the subepithelial basement membrane all along the entire human alimentary canal. The major constituents of the basement membrane, laminin and collagen type IV, were found continuously within the subepithelial basement membrane. Along the cryptvillus axis, no apparent gradient of the relative proportions of these two macromolecules within the basement membrane was observed immunohistologically. It has been suggested that the differentiated epithelial cells may contribute to the synthesis of the basement membrane proteins. Direct evidence for this possibility, however, is lacking. In contrast, production of fibronectin, interstitial collagens and probably 
collagen type IV by undifferentiated intestinal epithelial cells of an epithelial cell line in vitro has been reported.$^{89}$ These rapidly proliferating epithelial cells share some features of crypt cells but do not differentiate when cultured as a plain monolayer. As the degree of differentiation and the type of matrix produced by a certain cell type are generally closely correlated, it is difficult to extrapolate the observations with undifferentiated cell lines to the behaviour of fully differentiated cells.

The properties of the subepithelial fibroblasts have yet to be defined beyond their morphological features. ${ }^{10-12}$ Most likely, they secrete the collagens and other macromolecules of the connective tissue within the lamina propria ('reticulin', 'ground substance'). We have obtained evidence that different subpopulations of fibroblast-like cells coexist in the lamina propria and the submucosa. ${ }^{7}$ Whether the subepithelial fibroblasts are involved in basement membrane formation is not clear. During ontogenesis, the mesenchymal cells exert a powerful influence on the fetal endoderm and the importance of the mesenchyme for the maturation of the intestinal mucosa has been clearly documented. ${ }^{13-15}$

In this study, we present evidence for the biosynthesis of basement membrane proteins by primary intestinal epithelial cells and for the requirement of mesenchyme for the deposition of a complete basement membrane. An experimental model is proposed which permits the investigation of basement membrane formation in a chemically defined medium.

\section{Methods}

\section{EXPLANT CULTURES}

Fetal NMRI mice and fetal Sprague-Dawley rats were obtained by hysterectomy at a fixed gestational age. Day 0 of gestation was defined as the day of appearance of the vaginal plug.

The small intestine of fetal mice at day 14-16 and of fetal rats at day $15-17$ was removed at $4{ }^{\circ} \mathrm{C}$ with the help of a dissecting microscope and immediately placed into ice cold Dulbecco's modified Eagle's medium ('DMEM') containing $4.5 \mathrm{~g} / 1$ glucose (Boehringer, Mannheim, West Germany).

Human fetal small intestine was obtained from two therapeutic hysterectomies during the 11th and 12th week of pregnancy, respectively. Explant cultures were set up under identical conditions after transport of the fetal intestines to the laboratory in ice cold Leibovitz L-15 medium (Biochrom, West Berlin). Out of a total of 28 explants originating from the ileum and jejunum, 24 developed a large primary epithelial monolayer and were processed for immunofluorescence or electron microscopy. No attempts were made to use serum free medium for culturing human intestinal explants.
Of the murine fetal intestines, only $1-2 \mathrm{~cm}$ proximal to the ileocaecal junction were retained, minced into $1 \times 1 \mathrm{~mm}$ fragments and placed into a culture dish. For the immunofluorescence studies, the explants were grown on plastic Petri dishes (Falcon, Oxnard, USA) or on glass coverslips pretreated for one hour at $60{ }^{\circ} \mathrm{C}$ in $0.1 \mathrm{M} \mathrm{HCl}$, one hour at $80^{\circ} \mathrm{C}$ in aqua dest and stored in $70 \%$ alcohol. For the electron microscopical examinations, fetal explants were grown on Thermonox slides (Lux Scientifique, Naperville, USA). In one set of experiments, glass coverslips and Thermonox slides were covered with either native laminin (a gift of Dr R Timpl, Max Planck Institute, Munich), collagen type I and IV (prepared from human placenta by Dr D Schuppan) or fibronectin (Biochrom, West Berlin) in the following manner: these proteins were diluted in $0.2 \mathrm{M}$ ammonium bicarbonate or in $0.5 \mathrm{M}$ acetic acid at $50 \mu \mathrm{g} / \mathrm{ml}$ and $1 \mathrm{ml}$ of each solution per $35 \mathrm{~mm}$ Petri dish containing the coverslip was then allowed to evaporate under an ultraviolet light source.

Intestinal mesenchymal cells from the same sources were readily obtained from longer jejunal segments which were slit open longitudinally and placed into the culture dishes with the epithelial surface uppermost. Initially, all the explants were nourished by as little medium as possible $(2-3 \mathrm{ml} / 10 \mathrm{~cm}$ dish $)$ to promote the attachment of the intestinal fragments to the dish. The volume of the medium was then slowly increased to $12 \mathrm{ml} /$ dish.

\section{CULTURE CONDITIONS}

Explant cultures were incubated in DMEM (see above) plus $10 \%$ fetal calf serum (Biochrom, West Berlin), $4 \mathrm{mM}$ glutamine (Biochrom, West Berlin), $50 \mathrm{U} / \mathrm{ml}$ penicillin, $50 \mu \mathrm{g} / \mathrm{ml}$ streptomycin (both from Sigma, Munich, West Germany) and $140 \mathrm{mU} / \mathrm{ml}$ insulin (Hoechst, Frankfurt, West Germany) under $8 \% \mathrm{CO}_{2}$ in air at $35^{\circ} \mathrm{C}$. Hormone-supplemented, serum free medium consisted of: DMEM plus $50 \mu \mathrm{g} /$ $\mathrm{ml}$ transferrin, $50 \mu \mathrm{g} / \mathrm{ml}$ ascorbic acid, $50 \mathrm{ng} / \mathrm{ml}$ epidermal growth factor, $1 \mu \mathrm{g} / \mathrm{ml}$ dexamethasone (all from Sigma, Munich, West Germany), $2 \mathrm{mM}$ glutamine (Biochrom, West Berlin) and $50 \mathrm{mU} / \mathrm{ml}$ insulin (Hoechst, Frankfurt, West Germany). Medium was exchanged every three to four days.

\section{HISTOCHEMICAL TECHNIQUES}

The presence of alkaline phosphatase, lactase and a-glucosidase was documented histochemically in unfixed explant cultures according to Gutschmidt et al. ${ }^{1617}$

\section{ELECTRON MICROSCOPY}

For transmission electron microscopy, the explants grown on Thermonox slides were fixed in $1 \%$ glutaraldehyde, $1 \%$ tannin in $0.2 \mathrm{M}$ phosphate 
buffered saline, postfixed in $1 \%$ osmium tetraoxide and embedded in Mikropal according to Merker and Barrach. $^{18}$

\section{IMMUNOFLUORESCENCE}

Preparation of antigens, production of antisera and purification and characterisation of antibodies to collagen type I, III, IV, and VI, procollagen type I and III, laminin fragments P1 and undulin were carried out in our laboratories and have been described in detail elsewhere. ${ }^{19-23}$ Anti-fibronectin antibodies were either obtained commercially (Dakopatts, Hamburg, West Germany), or as a gift by Prof Hörmann, Max Planck Institute, Munich, West Germany. Anticytokeratin antibodies, antibodies to factor VIII, bovine intestinal alkaline phosphatase and the fluoresceine (FITC)- or rhodamine (TRITC)conjugates (second antibodies) were obtained from Dakopatts, Hamburg, West Germany. The conjugates were used diluted $1: 20$ to $1: 100$ with phosphate buffered saline. Indirect immunofluorescence was done as follows: cell cultures were extensively washed with plain DMEM at $36^{\circ} \mathrm{C}$, fixed either with $1 \%$ buffered formalin at $4{ }^{\circ} \mathrm{C}$ followed by a wash with buffered $0 \cdot 2 \mathrm{M}$ glycine to enhance good preservation or with a 1:1 mixture of chloroform/acetone for 10 minutes to ensure intracellular staining. As formalin fixation slightly diminishes antigenicity, two explants were always used air dried without any fixation for comparison but these were not documented.

Non-immune rabbit IgG, rabbit serum and goat serum were used as controls for unspecific staining. First and second antibodies were incubated with the explant cultures for an hour each, followed by extensive washes with $1 \%$ bovine albumin in phosphate buffered saline.

\section{Results}

DEVELOPMENT OF FETAL INTESTINAL

EXPLANTS IN VITRO

Within 12-24 hours of initiation of the explant cultures, the intestinal fragments adhered to the culture dishes and epithelial outgrowth was seen. Only those explants with exclusively epithelial outgrowth within the first two days were maintained in culture (60-80\% of all explants). All the others were discarded. The primary epithelial monolayer is readily distinguishable from other cells which may migrate from the fetal intestinal mucosa but in every series of explants some of them were assayed for the presence of cytokeratin and the absence of factor VIII by immunofluorescence. The primary epithelial monolayer consisted of tightly packed, small, polygonal cells which often form a thick rim at the leading edge (Fig. 1a, b). These epithelial cells proliferated rapidly, encircling the original piece of mucosa within four to eight days. Sometimes the intestinal fragments did not adhere at all to the culture dish and continued to float in the culture medium. (Under these circumstances the mucosa will grow into three-dimensional, vital 'organ cultures' as has been described before. ${ }^{24}$ ) These were removed from the Petri dishes because their presence seemed to diminish the outgrowth of the primary epithelial monolayer from the adherent explants. While the primary epithelial cells continued to proliferate at the periphery of the explants maintaining a flat, well recognisable cytoplasm and a central nucleus, the pericentral zone of the epithelium began to show structural changes about three to five days after explantation. At this time, the pericentral zone appeared as a very dense cell layer by phase contrast microscopy. Very little cytoplasm was observed in these pericentral epithelial cells and the nuclei were no longer distinguishable. The border between the pericentral zone and the peripheral epithelial monolayer was usually rather abrupt although in some instances a more gradual transitional zone developed. When the distribution of the activity of three brush border enzymes was studied histochemically at this stage of the explant cultures, only the central and pericentral zones were stained (Fig. 2a). The entire periphery which represents the primary epithelial monolayer remained consistently negative for a-glucosidase and lactase. A 'mosaic' distribution of alkaline phosphatase-positive and -negative cells were found in the primary epithelium indicating that individual cells closer to the original explant express enzyme activity (Fig 2a). None of the brush border enzymes was seen at the leading edge of a primary epithelial monolayer. These findings indicated that epithelial cytodifferentiation had occurred in vitro not only in the central but also in the pericentral zone of the epithelial explant at a time when the primary epithelial monolayer had not acquired these features of maturation.

\section{ULTRASTRUCTURAL ASPECT OF THE EXPLANT CULTURES}

Ultrastructural analysis of transverse sections of the explant cultures confirmed the existence of a polarised intestinal epithelium in the pericentral zone at a considerable distance from the original piece of mucosa (Fig. 1c, 1d, 1e). Apparently, a gradient of differentiation had developed from the centre (original mucosa) towards the periphery of the epithelial outgrowth: the peripheral cells of the primary monolayer were flat, joined by gap functions and covered by only very sparse microvilli. They resembled cells from epithelial cell lines such as the IEC 6 cells $^{25}$ or another intestinal epithelial cell line recently established in our own laboratory. ${ }^{26}$ In the peripheral monolayer some of the cells seemed to overlap each other. Amorphous and cross-striated, 

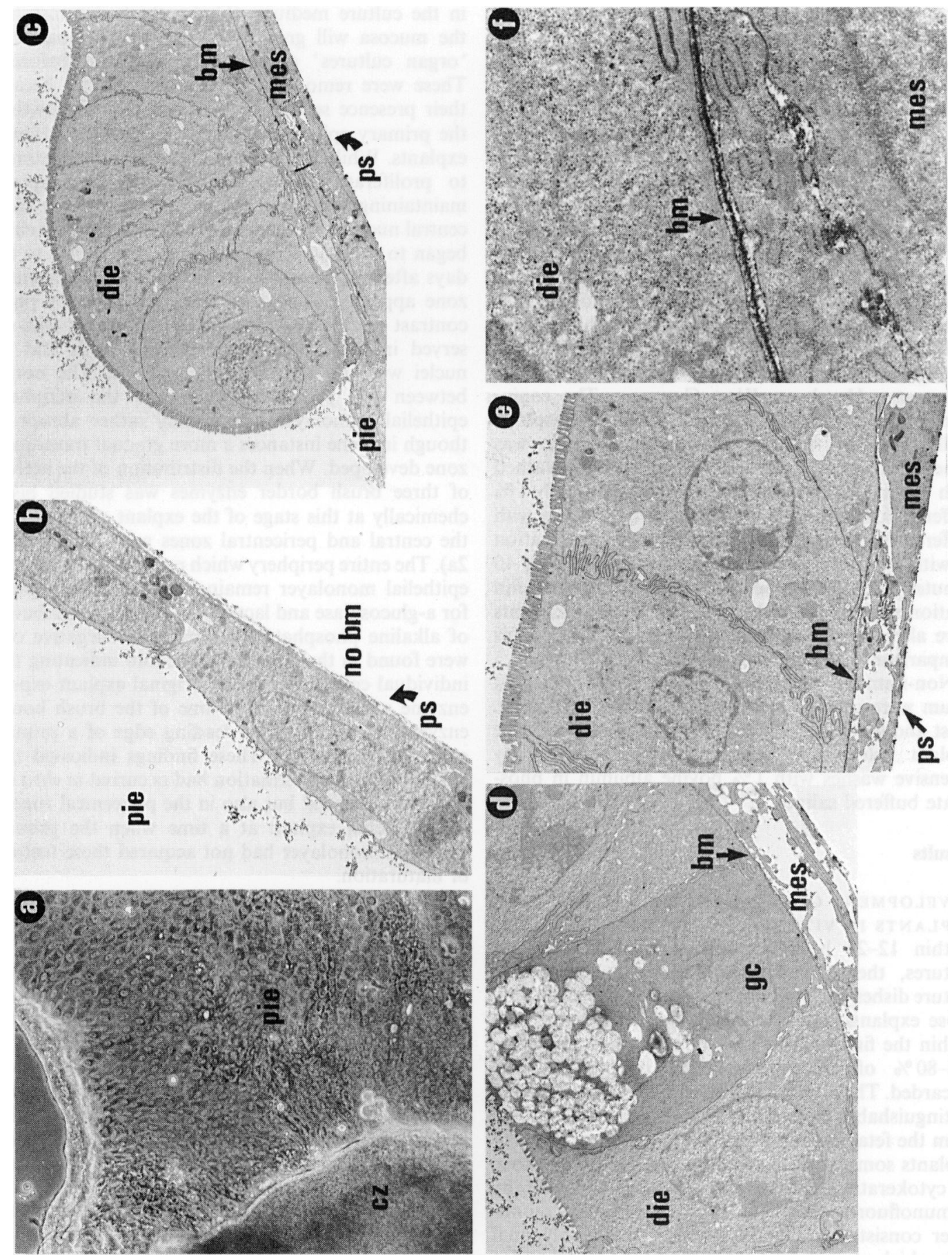
collagenous material but certainly no basement membrane was found deposited under these cells. This behaviour is again reminiscent of intestinal epithelial cell lines which cannot organise true basement membranes by themselves in vitro.

In contrast, an incomplete basement membrane appeared at the border between the peripheral and the pericentral zone which became continuous within two to three epithelial diameters towards the centre. At high magnification, a lamina densa could be resolved within the basement membrane identical to the structure of authentic intestinal basement membranes (Fig. If). The appearance of the basement membrane coincided precisely with the abrupt onset of polarisation of the epithelium of the pericentral zone. At the same time, the basement membrane was observed to reach from the centre of the explant just as far as the outgrowth of mesenchyme which had proliferated from the original piece of mucosa in between the primary monolayer and the culture dish (Fig. 1c, le).

Thus, in transverse sections of five to 20 day old explant cultures, the pericentral zone was characterised by a polarised epithelium covering a complete basement membrane which demarcated the underlying mesenchymal layer. At the same time, the primary epithelium was still expanding as a flat, unpolarised monolayer on the plain culture dish surface.

The cells of the pericentral zone conveyed further features of differentiation: the cuboidal epithelial cells expressed a regular brush border, tight junctions and an extensively interdigitated lateral plasma membrane. Among them, occasional goblet cells were identified by their typical, apically oriented mucin granules (Fig. 1d). In the human fetal explants very few secretory cells, presumably neuroendocrine cells as evidenced by their basally located, electron-dense granules were recognised in the immediate proximity of highly polarised (columnar) cells in the pericentral zone close to the original piece of mucosa. No endocrine cells were found in the murine explants.
A columnar epithelium with broad intercellular spaces indicating active absorption covered the very centre of the explants. The nuclei of these cells appeared indented and, with respect to the morphology of the other cellular organelles, they much resembled the intestinal epithelium of suckling rats.

DISTRIBUTION OF BASEMENT MEMBRANE

PROTEINS AND MATRIX PROTEINS IN THE

FETAL EXPLANT CULTURES

Significant changes in the distribution of extracellular matrix proteins accompany the development of fetal intestinal explant cultures (Figs 2b-2f, 3a, b). By immunofluorescence, laminin was found abundantly intra- and extracellularly in the primary epithelial monolayer and also in individual cells migrating ahead of the leading edge. Extracellularly, it formed a delicate network quite distinct from the longer and thicker fibrils of fibronectin. The amount of intracellular laminin, however, was decreased dramatically in the pericentral, differentiated zone where a basement membrane had been laid down (Fig 3a, b). Most of the differentiated epithelial cells of the pericentral and central zones did not stain at all with antibodies to basement membrane proteins. By immunofluorescence, it is difficult to assess the plane of observation, but it was our definite impression that laminin was only observed in the plane of the basal plasma membrane of the polarised epithelium and not intracellularly.

Collagen type IV was essentially codistributed with laminin although intracellular staining of the primary monolayer was weaker compared with laminin and also compared with the intracellular amount of collagen type IV observed in intestinal epithelial cell lines. ${ }^{26}$ Extracellularly very little collagen type IV was found in the primary intestinal monolayer. No collagen type IV was observed within the differentiated intestinal epithelium immunohistologically.

Fibronectin was detected by a comparatively weak staining in the primary epithelial monolayer. Enhanced intracellular staining for fibronectin was

Fig. la-f Light (LM) - and transverse electron microscopical (TEM) aspect of fetal intestinal explants. a: Outgrowth of primary intestinal epithelium from the original piece of mucosa after four days in vitro: a homogenous epithelial monolayer of primary undifferentiated cells has formed $\times 100$, LM. $b$ : Ultrastructural aspect of the primary epithelial monolayer showing flat, unpolarised cells. A basement membrane has not been deposited. $\times 5000$, TEM. c: Differentiated intestinal epithelial cells at the border between the pericentral zone and the primary intestinal epithelium are crowding together forming a thicker ridge. They have extended as far as the mesenchymal cells. Note the disappearance of the subepithelial basement membrane at the border of the pericentral zone. $\times 4000, T E M . d:$ A goblet cell within the pericentral zone of differentiated cells. Note the continuous basement membrane at the basal plasma membrane of the differentiated enterocytes. $\times 6000, T E M$. e: Typical aspect of the epithelial cells within the pericentral zone displaying a regular brush border, tight junctions, extensively interdigitated lateral plasma membranes and a well defined basement membrane at the epithelial-mesenchymal interface. $\times 6000, T E M . f$ : Higher magnification of the subepithelial basement membrane in the pericentral zone revealing a dense inner layer (lamina densa). Amorphous extracellular material is found between mesenchymal cells. $\times 38000, T E M . b m=$ basement membrane, $c z=$ central zone equivalent to the original piece of mucosa, die $=$ differentiated intestinal epithelial cells, gc = goblet cell, mes = mesenchymal cells, pie = primary, undifferentiated intestinal epithelial cells, ps = plastic surface of culture dish. 

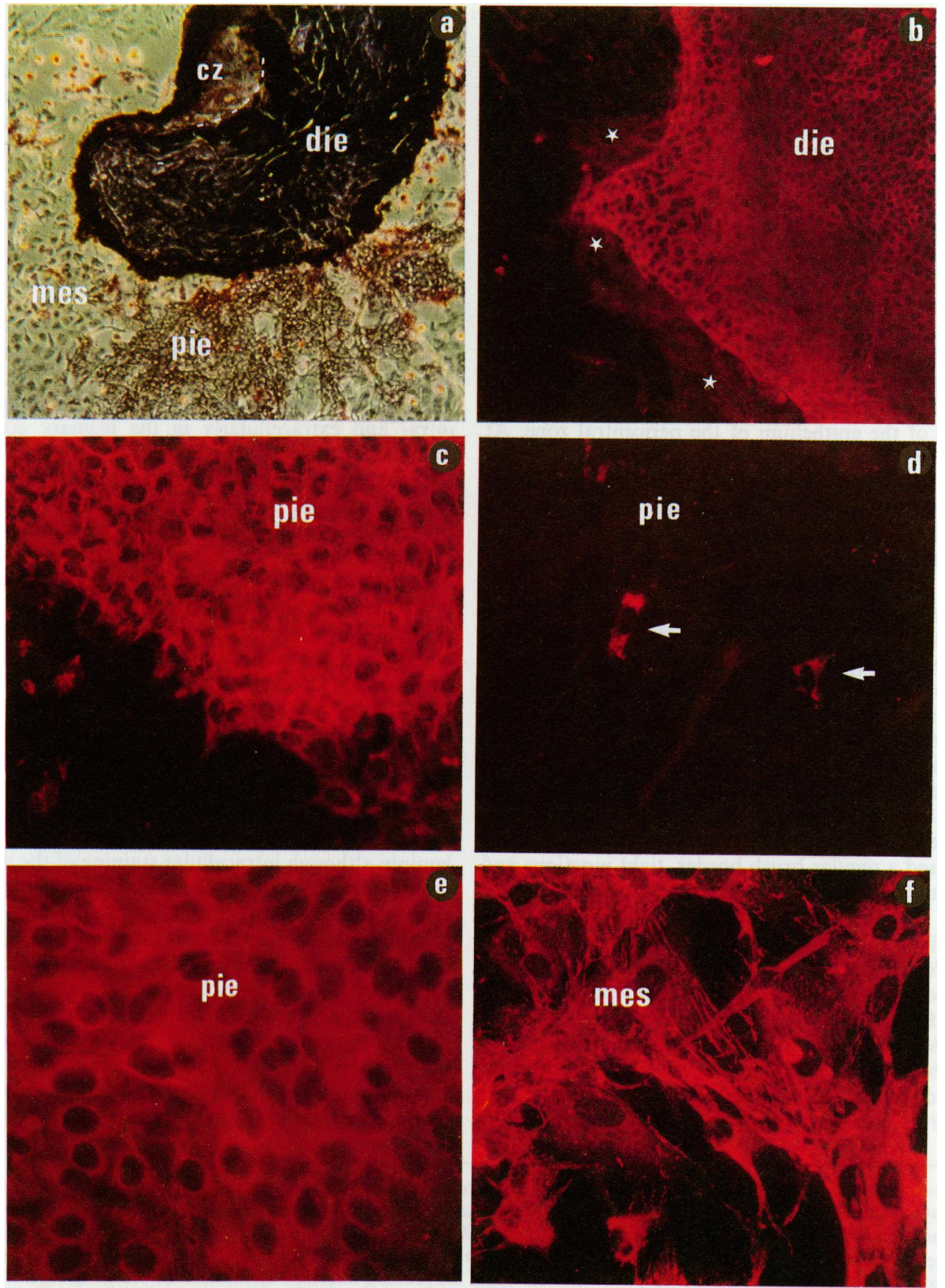

Fig. 2a-f Histochemical and immunohistological aspects of fetal intestinal explants. a: Intensive intestinal alkaline phosphatase activity within the pericentral and central zone is demonstrated histochemically in a two week old explant. Peripheral primary intestinal epithelial cells are more lightly stained, while the mesenchymal cells in the very periphery have no enzyme reactivity. $\times 100 . b:$ The presence of int alkaline phosphatase enzyme protein is documented with antibodies by immunofluorescence within the pericentral zone. Asterisks are placed on the adjacent, narrow region of undifferentiated cells expressing the enzyme protein to a lesser degree while the periphery remains negative. $\times 80 . c:$ Antibodies to laminin brilliantly decorate intra- and extracellular material within the primary intestinal epithelial cells. $\times 200 . d$ : Antibodies to procollagen type III single out rare individual mesenchymal cells that have overgrown the primary monolayer which is not stained by these antibodies. $\times 200$. e: Primary intestinal cells are stained by antibodies to collagen type IV mostly intracellularly. $\times 200 . \mathrm{f}:$ Typical mesenchymal cells that have proliferated from the intestinal mucosa are shown here to produce fibronectin by immunofluorescence. $\times 200 . c z=$ central zone, die $=$ differentiated intestinal epithelium, mes = mesenchymal cells, pie = primary intestinal epithelium, $s m c=$ smooth muscle cells. 

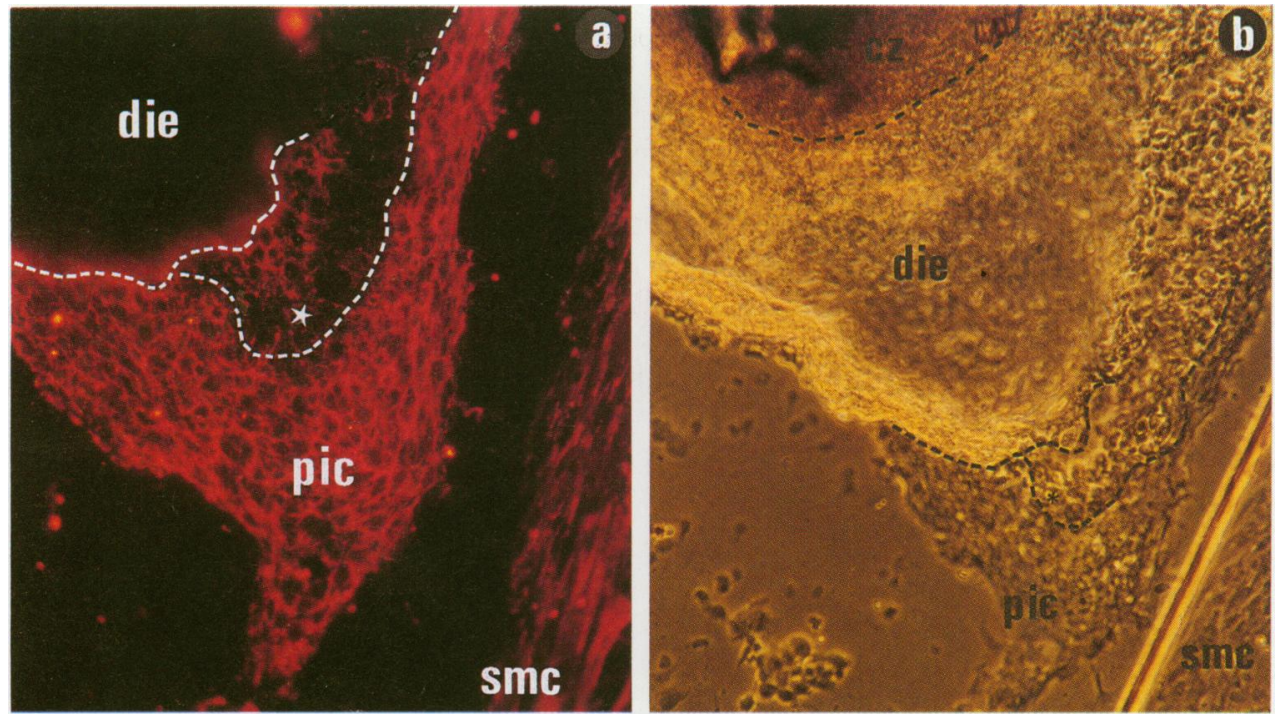

Fig. 3a, b Distribution of laminin in fetal intestinal explants at 12 days in vitro. a: immunofluorescence, $\times 80, b:$ phase contrast optics, $\times 100$. The pericentral zone containing differentiated intestinal epithelium is negative, while the primary, peripheral intestinal epithelial cells and extracellular material are heavily stained by these antibodies. The asterisks indicate a region just transforming to the differentiated state where staining is already decreasing. Due to the subepithelial invasion by the mesenchyme, the level of the peripheral zone is raised over that of the primary monolayer on the culture dish and is therefore not in focus. Smooth muscle cells are approaching the explant from the periphery, originating from another specimen. They are also clearly producing laminin. $c z=$ central zone, die $=$ differentiated intestinal epithelium, pic $=$ primary intestinal cells, smc $=$ smooth muscle cells.

remarked at the thick leading edge of the primary monolayer and in areas of intensive proliferation of epithelial cells reminiscent of the undifferentiated, highly proliferative intestinal epithelial cell lines which produce large amounts of fibronectin and deposit this protein as a dense network. ${ }^{826}$ In contrast, no fibronectin was identified intracellularly within the differentiated epithelium in vitro. Collagen type I, III and VI and the procollagens type I and III and undulin, all of which are macromolecules of the connective tissue in situ, were not detected in any primary or differentiated intestinal epithelial cell. The mesenchymal cells, however, migrating from the mucosa in vitro were heavily stained by antibodies to these interstitial macromolecules. It should be mentioned that intestinal smooth muscle cells produce basement membrane proteins and that these cells were equally stained by antibodies to collagen type IV and to laminin (Fig. 3a, b). Morphologically, they cannot be confused with intestinal epithelium. Further characterisation of the population of mesenchyme derived cells is under way.

In order to test whether single, distinct constituents of the extracellular matrix, namely laminin, collagen type I, III, IV and fibronectin could induce differentiation of the primary epithelial monolayer, we explanted the fragments onto glass coverslips coated with the respective proteins. Essentially, however, no alterations of the scheme of development as observed on plain plastic dishes seemed to take place. Outgrowth of the primary monolayer did not vary on the different substrates. Epithelial differentiation was observed only in the immediate vicinity of viable mesenchyme and was certainly not inducible by any single protein.

Defined, serum free medium supplemented with transferrin, epidermal growth factor, dexamethasone, glucagon, insulin and ascorbic acid generated the same development of the fetal murine mucosa in vitro as serum supplemented medium, although initial attachment of the fragments was much slower. It is therefore possible to study basement membrane deposition by intestinal epithelia under chemically defined conditions. We have now begun to analyse the effect of individual growth factors in this system.

\section{Discussion}

The study presented here demonstrates the detection of basement membrane proteins within primary fetal intestinal epithelial cells. Concomitantly to the induction of polarisation and differentiation of this 
primarily undifferentiated epithelium, an authentic basement membrane is detected by electron microscopy at the epithelial/mesenchymal interface. Within the differentiated epithelial cells, basement membrane proteins are detectable immunohistologically only in trace amounts. Evidence for the differentiation of the primary intestinal epithelium in vitro is provided by ultrastructural analysis and by histochemical demonstration of brush border enzymes.

The time course of events suggests that after the primary epithelial monolayer has proliferated from the original piece of mucosa, intestinal mesenchyme also begins to grow out of the mucosa invading the space between the primary epithelium and the surface of the culture dish. Apparently the intimate association of the fetal mesenchyme with the primary fetal epithelium induces the formation of a basement membrane and, simultaneously, epithelial cytodifferentiation. In the absence of mesenchyme, neither a basement membrane nor brush border activity is observed. Only alkaline phosphatase enzyme activity may be detected within individual, morphologically undifferentiated cells in a mosiac pattern.

We think that the most likely explanation for the dramatic decrease of intracellular basement membrane proteins within the differentiated epithelium is, that, upon differentiation, the intracellular pool of laminin and collagen type IV drops to such a low level that they are no longer detected by immunofluorescence. It seems highly likely that the mesenchyme induces the epithelial cells to secrete basement membrane proteins at their basal plasma membrane. Active participation of the mesenchymal cells in basement membrane biosynthesis, however, is also conceivable so that basement membrane formation is organised by both tissues in a coordinated fashion. The assembly of intrinsic basement membrane proteins at the basal plasma membrane requires specific receptors - one of which, the laminin receptor, has recently been identified on intestinal cells. ${ }^{27}$ Whether the polarisation of the epithelial cells is a concomitant alteration of the epithelial phenotype or whether polarisation is a prerequisite for the direction of secretion and the formation of a true basement membrane remains to be resolved.

The deposition of basement membrane proteins by induced but morphologically still undifferentiated cells has been demonstrated in another model in vitro: Ekblom et al detected the very early appearance of laminin and collagen type IV in the induced kidney mesenchyme before tubule formation (epithelial differentiation) occurred. ${ }^{28}$ Changing patterns of the distribution of matrix proteins accompanying epithelial differentiation have been observed in a variety of tissues in vivo and in vitro (for reviews $\operatorname{se}^{42930}$ ).
Judging from these studies and our own experience, it is difficult to provide unequivocal evidence for the $d e$ novo biosynthesis of basement membrane proteins by mature epithelial cells. A novel approach will be the estimation of specific mRNA levels for laminin and collagen type IV by in situ hybridisation and we are currently engaged in this research in application to intestinal cells.

Epithelium-matrix-mesenchyme interactions are complex events promoting cytodifferentiation and tissue organisation. The requirement of viable mesenchyme for the maturation of the intestinal epithelium and the deposition of a basement membrane is indicated by this model in vitro, while previous reports have already established the importance of fetal mesenchyme in grafting experiments. ${ }^{13-15}$ Another study revealed the intimate anatomical association of the epithelium with its underlying mesenchyme by cellular processes through gaps in the basement membrane during organogenesis in a phase of rapid intestinal maturation. ${ }^{10}$

We have not identified a single matrix component that would simulate the effect of living mesenchymal cells in vitro. We have not, however, tested all potential molecular candidates. It is equally conceivable, that the combination of a minimal number of matrix proteins in combination with heparansulphate proteoglycan is required to induce epithelial maturation..$^{31}{ }^{32}$ Heparansulphate proteoglycan is also an intrinsic component of the intestinal basement membrane. ${ }^{33}$

The nature of epithelial-fibroblast interactions in the adult intestinal mucosa may differ from those during fetal life. The crypt-villus axis as a gradient of epithelial maturation is not in every aspect comparable to the differentiation of the intestinal epithelium during organogenesis. We need more detailed and more quantitative investigations of the cells involved in respect to matrix production and matrix assembly to elucidate these important relationships.

The expert technical assistance of E Rettig and $\mathrm{H}$ Krüger is greatfully acknowledged. This work was supported by the Deutsche Forschungsgemeinschaft, project no. RI 136/12-1.

\section{References}

1 Kleinman HK, Klebe RJ, Martin GR. Role of collagenous matrices in the adhesion and growth of cells. $J$ Cell Biol 1981; 88: 473-85.

2 Piez KA, Reddi AH, eds. Extracellular matrix biochemistry. New York/Amsterdam: Elsevier, 1984.

3 Porter R, Whelan J, eds. Basement membranes and cell movement. Ciba Foundation Symposium 108. London: Pitman, 1984.

4 Trelstad $\mathrm{R}$, ed. Role of extracellular matrix in development. New York: Alan R Liss, 1984. 
5 Martinez-Hernandez A, Amenta PS. The basement membrane in pathology. Lab Invest 1983; 48: 656-77.

6 Martin GR, Kleinman HK. The extracellular matrix in development and disease. Semin Liver Dis 1985; 5: 147-56.

7 Hahn U, Schuppan D, Hahn EG, Riechen EO. The extracellular matrix of the intestinal mucosa. 1986; (submitted)

8 Quaroni A, Isselbacher KJ, Ruoslahti E. Fibronectin synthesis by epithelial crypt cells of rat small intestine. Proc Natl Acad Sci USA 1978; 75: 5548-52.

9 Quaroni A, Trelstad R. Biochemical characterization of collagens synthesized by intestinal epitheloid cell cultures. J Biol Chem 1980; 255: 8351-61.

10 Mathan M, Hermos JA, Trier JS. Structural features of the epithelio-mesenchymal interface of rat duodenal mucosa during development. J Cell Biol 1972; 52: 577 88.

11 Marsh MN, Trier JS. Morphology and cell proliferation of subepithelial fibroblasts in adult mouse jejunum. Gastroenterology 1972; 67: 622-45.

12 Kaye GI, Lane N, Pascal RR. Colonic pericryptal fibroblast sheath: replication, migration and cytodifferentiation of a mesenchymal cell system in adult tissue. Gastroenterology 1968; 54: 852-65.

13 Haffen K, Lacroix B, Kedinger M, Simon-Assman P. Inductive properties of fibroblastic cell cultures derived from rat intestinal mucosa in epithelial differentiation. Differentiation 1983; 23: 226-33.

14 Lacroix B, Kedinger M, Simon-Assman P, Haffen K. Effects of human fetal gastroenteric mesenchymal cells on some developmental aspects of animal gut endoderm. Differentiation 1984; 28: 129-335.

15 Kedinger M, Simon-Assman P, Lacroix B, Marxer A, Hauri HP, Haffen K. Fetal gut mesenchyme induces differentiation of cultured endodermal and crypt cells. Dev Biol 1986; 113: 474-83.

16 Gutschmidt S, Kaul W, Riecken EO. A quantitative histochemical technique for the characterization of $\alpha$ glucosidases in the brush border membrane of rat jejunum. Histochemistry 1979; 63: 81-101.

17 Gutschmidt S, Lange U, Riecken EO. In situ- measurements of protein contents in the brush border region along rat jejunal villi and their correlations with four enzyme activities. Histochemistry $1980 ; 72$ : 467-79.

18 Merker HJ, Barrach HJ. The morphology of basement membrane formation. Eur J Cell Biol 1981; 26: 11120.

19 Rhode H, Vargas L, Hahn EG, Kalbfleisch H, Bruguera M, Timpl R. Radioimmunoassay for type III procollagen peptide and its application to human liver disease. Eur J Clin Invest 1979; 9: 451-9.
20 Risteli J, Bächinger HP, Engel J, Furthmayer H, Timpl R. 7 s- collagen: characterization of an unusual basement membrane structure. Eur J Biochem 1980; 108: 23950.

21 Schuppan D, Rühlman T, Hahn EG. Radioimmunoassay for human type VI collagen and its application to tissue and body fluids. Anal Biochem 1985; 149: 23847.

22 Schuppan D, Becker J, Boehm H, Hahn EG. Immunofluorescent localization of type $\mathrm{V}$ collagen as a fibrillar component of the interstitial connective tissue of human oral mucosa, artery and liver. Cell Tiss Res 1986; 243: $535-43$.

23 Schuppan D, Besser M, Schwarting R, Hahn EG. Radioimmunoassay for the carboxyterminal cross-linking domain of type IV procollagen in body fluids. J Clin Invest 1986; 78: 241-8.

24 Quaroni A. Development of fetal rat intestine in organ and monolayer culture. J Cell Biol 1985; 100: 161122.

25 Quaroni A, Wands J, Trelstad RL, Isselbacher KJ. Epitheloid cell cultures from rat small intestine. $J$ Cell Biol 1979; 80: 248-65.

26 Hahn U, Schuppan D, Hahn EG, Merker HJ, Riecken EO. 1986; (in preparation)

27 Hand PH, Thor A, Schlom J, Rao CN, Liotta L. Expression of laminin receptor in normal and carcinomatous human tissues as defined by a monoclonal antibody. Cancer Res 1985; 45: 2713-17.

28 Ekblom P, Alitalo K, Vaheri A, Timpl R, Saxen L. Induction of a basement membrane glycoprotein in embryonic kidney: possible role of laminin in morphogenesis. Proc Natl Acad Sci USA 1980; 77: 485-9.

29 Ekblom P, Vestweber D, Kemler R. Cell-matrix interactions and cell-adhesion during development. Ann Rev Cell Biol 1986; 2: 27-49.

30 Timpl R, Dziadek M. Structure, development and molecular pathology of basement membranes. Int Rev Exp Pathol 1986; 29: 1-112.

31 Martin GR, Kleinman HK, Terranova VP, Ledbetter S, Hassell JR. The regulation of basement membrane formation and cell-matrix interactions by defined supramolecular complexes. In: Porter $\mathbf{R}$, Whelan $\mathrm{J}$, eds. Basement membranes and cell movement. Ciba Foundation Symposium 108, London: Pitman, 1984: 197-209.

32 Kleinman HK, Cannon FB, Laurie GW, Hassel JR, Aumailley M, Terranova VP, Martin GR. Biological activities of laminin. J Cell Biochem 1985; 27 : 317-25.

33 Laurie GW, Leblond CP, Martin GR. Localization of type IV collagen, laminin, heparansulfate proteoglycan and fibronectin to the basal lamina of basement membranes. J Cell Biol 1982; 95 : 340-4. 